\title{
Numerical and Experimental Evaluation of Hydrodynamic Bearings Applied to a Jeffcott Test Bench
}

\author{
Everton C. Medeiros \\ São Paulo State University - Campus of Guaratinguetá, Av. Dr. Ariberto Pereira da Cunha, 333, Guaratinguetá, \\ São Paulo, Brazil.
}

Airton Nabarrete

Aeronautics Institute of Technology, P. Marechal Eduardo Gomes, 50, São José dos Campos, São Paulo, Brazil.

\author{
Marcela A. Cruchaga \\ Universidad de Santiago de Chile, P Av. Bdo. O’Higgins 3363, Estación Central, Santiago, Chile.
}

\author{
Willy R. P. Mendonça and Mauro H. Mathias \\ São Paulo State University - Campus of Guaratinguetá, Av. Dr. Ariberto Pereira da Cunha, 333, Guaratinguetá, \\ São Paulo, Brazil.
}

\section{(Received 25 August 2020; accepted 18 December 2020)}

\begin{abstract}
Merging analytical and numerical models with experimental results improve the behaviour predictions of mechanical elements applied to rotor machinery, such as the bearings. This work aims to present the design of a hydrodynamic bearing prototype, a comparison and validation between the numerical and experimental results of critical speeds, and the differences of behaviour when the bush geometries and lubrication are changed. The bush geometries and the fluid film properties are analysed by measuring the dynamic behaviour of a rotor supported by these bearings. The experimental evaluation is based on measuring the Jeffcott test bench supported in a pair of bearings, showing the anisotropic behaviour caused by the stiffness difference in horizontal and vertical directions. It also presents an optimization of bushings for isotropic conditions when they were changed for different geometries (elliptical, offset halves) and different materials with boundary lubrication. This detailed study shows how the dynamic behaviour of rotating machinery can be predicted using numerical models and its validation by a test rig. Results also show how the vibration occurs if the bushes geometries are modified or its lubrication condition is changed.
\end{abstract}

\section{INTRODUCTION}

In a rotating assembly the bearings are the elements responsible for the support and support of the rotor element. According to ISO 1925 the definition of a rotor is: a body supported by bearings that can rotate about a fixed axis in space. ${ }^{1}$ In all industrial sectors the presence of bearings in the axle support is easy to see, in the automotive sector, for example, simulated frictional power losses on the bearings supporting the crankshaft of an internal combustion engine, holding the bearings responsible for retaining $16 \%$ of that power. ${ }^{2}$

However, in most of the supporting elements the analysis of their behaviours is not trivial and their phenomena are in a nonlinear field, such as in ball/roller bearings $\mathrm{s}^{3,4}$ and hydrodynamic bearings. ${ }^{5,6}$ The use of hydrodynamic bearings in the support of rotary machines are widely used due to their high levels of reliability and durability. ${ }^{7}$

The hydrodynamic bearings work with the use of lubrication between the bushing and the journal. Due to the force of the oil generating a small displacement in the journal and small rotations on the equilibrium position, during the formation process until the stabilization of the oil film. This process is described as a non-linear situation mainly due to the effects of the bear- ings, dampers or other causes, such as the presence of cracks. ${ }^{8}$ Therefore, the estimation of parameters of hydrodynamic bearings becomes a difficult task, with the need for the solution of mixed equations between the field of dynamics and the field of fluid mechanics.

In these types of bearings, the formulations generate not only rigidity parameters in two directions, but also cross components due to the presence of the oil film. Li et al. presented a method of identifying the oil film coefficients through the implementation of the Green function and its regularization, then the equivalent load reconstruction was obtained. ${ }^{9}$ Concluding, therefore, the estimation of rigidity and damping parameters for a flat cylindrical hydrodynamic bearing. The influence of coupling between stiffnesses is seen in a tilting pad type bearing for a vertical rotor. ${ }^{10}$ Mazer cited that these crossstiffness parameters generate tangential and rotational force components, thus leading to instability problems. ${ }^{11}$

When designing a hydrodynamic bearing, knowledge of the instability limits is necessary for the operation of the rotating assembly to be in a safety region. The phenomenon of instability self-excites vibrations in the bearing, having no relation to the critical velocity or other defects. Wang et al. presented a 
discussion about instability and its effects on the dynamic behaviour. The anisotropy that caused the instability was related to transverse crack at the shaft. ${ }^{12}$

Huang et al. showed a simpler method for obtaining these limits. ${ }^{13}$ This method was based on the exchange in the state vector, from $c=[X Y \dot{X} \dot{Y}]$ to $c=[\varepsilon \phi \dot{\varepsilon} \dot{\phi}]$, avoiding later in the coordinate transformation operation.

The motion equation to be solved for dynamic analysis: ${ }^{13}$

$$
[M] \cdot \ddot{\vec{W}}+([G]+[C]) \cdot \dot{\vec{W}}+[K] \cdot \vec{W}=\vec{f} .
$$

In the equation: $[M]$ was the mass matrix; $[G]$ was the gyroscopic effect matrix; $[C]$ was the damping matrix; $[K]$ was the stiffness matrix; $\vec{W}$ was the displacement nodal vector; $\vec{f}$ was the force nodal vector. The gyroscopic effect matrix $[G]$ must be considered because of its relevance on the finite element rotordynamic analysis of large machines. ${ }^{14}$

The use of different geometries for the bushings of hydrodynamic bearings is a viable alternative for the solution of instability problems. ${ }^{15}$ Bhasker et al. conducted experimental studies of hydrodynamic pressure and oil film thermal analysis in bearings of the type "Offset-Halves". ${ }^{16}$ Rahmani et al. studied the performance and stability variations when the shape of bushes was elliptical. ${ }^{17}$ Ostayen and Beek made thermal studies in "Lemon" shaped bushings, detecting an improvement in the stability and thermal aspect as well. ${ }^{18}$ Urbiola-Soto et al. analysed the optimization of fixed shoe or lobes bearings through the best response of their surface, using the Design of Experiments (DOE) technique. ${ }^{19}$

Besides the variation of the geometry of the bushing, the application of different types of materials and different construction concepts of the bushings, with the use of composites for example, also appeared as a solution for better dynamic performance of the hydrodynamic bearings. Some authors propose different applications of different materials in the bushings and in each situation a certain improvement can be achieved. ${ }^{20-23}$

This work aims to present a comparison between the numerical simulation and experimental analysis from a fixed circular hydrodynamic bearing applied to a Jeffcott. It also presents experimental results of different developed types of bushings, and kind of lubrication, to decrease the anisotropic level and consequently possible instability effects caused in usual hydrodynamic bearings system.

\section{METHODOLOGY}

Journal bearing design is complex. It envolves optimizing clearances, bearing length, minimum film lubricant and other parameters. For this work, firstly a set of hydrodynamic bearings using fixed and cylindrical geometry bushings was proposed. However, the bearing assembly should be designed with interchangeability and should be made by changing the component of the bushing for another without difficulty. In addition, the feed system, which will be elaborated on in the following item, should be versatile and simple in design and operation, so there is no pressure drop that could influence the fluid feed pressure.

The methodology for bearing design starts with the $L / D$ ratio, i.e., a ratio between the length and inner diameter of bearing sleeve. A change in this initial step may result in changes in the stability limit and subsynchronous vibration frequencies.

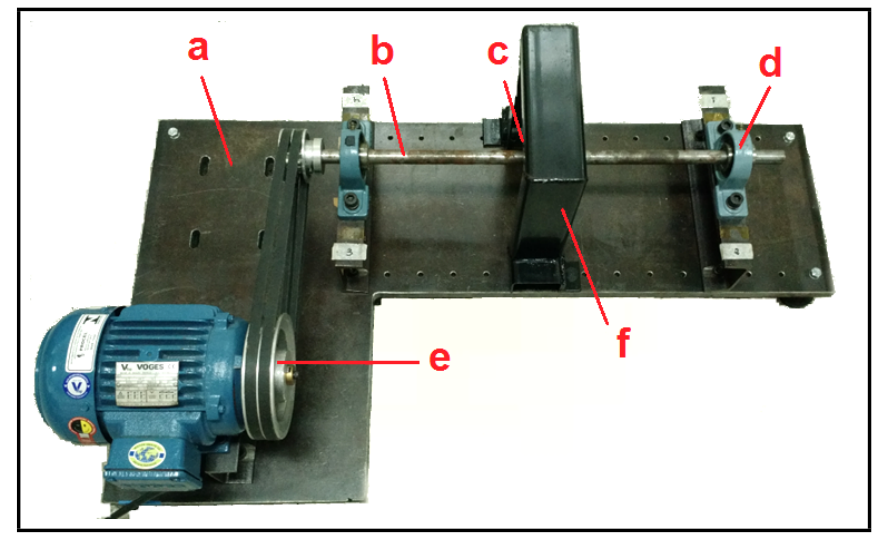

Figure 1. Jeffcott test rig. ${ }^{24}$

Table 1. Bearing perfomance factors.

\begin{tabular}{||c|c|c|c||}
\hline Factor & Symbol & Values & Units \\
\hline Sommerfeld number & $S$ & 7.703 & - \\
L/D ratio & $L / D$ & 0.95 & - \\
Minimum film thickness & $h_{0}$ & 0.0245 & $\mathrm{~mm}$ \\
Eccentricity & $E$ & 0.02 & - \\
Angular position & $\Phi$ & 84 & Degrees \\
Friction coefficient & $F$ & 0.35 & - \\
Total flow & $Q$ & 5.94 & $\mathrm{~L} / \mathrm{h}$ \\
\hline
\end{tabular}

The test rig where the bearing was applied consists of a rotor shaft with $0.020 \mathrm{~m}$ of diameter. Therefore, the inner diameter $(D)$ of the bush should be $0.020 \mathrm{~m}$. The length $(L)$ after machining process was $0.019 \mathrm{~m}$, obtaining the $L / D$ ratio equals to 0.95 .

The machine where the set of bearings was applied is described by Medeiros et al. ${ }^{24}$ Figure 1 shows the main components: (a) SAE 1020 main base with $0.030 \mathrm{~m}$ of thickness and weight of approximately $90 \mathrm{~kg}$; (b) SAE 1020 shaft with $0.020 \mathrm{~m}$ of diameter and weight of approximately $1.77 \mathrm{~kg}$; (c) SAE 1020 disk with $0.200 \mathrm{~m}$ of diameter, weight of $4.38 \mathrm{~kg}$; (d) assembly points for bearings; (e) drive system using an electric engine with 1471 Watts of power, nominal rotation speed of $3600 \mathrm{rpm}$, powered by a frequency inverter controller and set of pulleys and belts for magnify the speed by a 2:1 ratio; and (f) disk protection.

\subsection{Hydrodynamic Bearing Design}

The bush was made by brass TM23, the machining by a horizontal lathe and adjusted internally with a fixed-type reamer of $\varnothing 20 \mathrm{~mm} \mathrm{H7}$, thus obtaining a radial clearance of $0.005 \mathrm{~mm}$ and a nominal average roughness $(R a)$ of $0.8 \mu \mathrm{m}$. The lubricant fluid was a mineral oil SAE 32 without additives, the dynamic viscosity was around $\mu=125 \mathrm{cP}$ or $0.13 \mathrm{~Pa}$.s.

After establishing some of the geometry values for the bearing sleeve, the working fluid and its maximum operating rotation, Table 1 presents the bearing performance factors. Figure 2 shows the bearing mounted on the Jeffcott test rig using the developed cylindrical bush.

\subsection{Fluid Feed System}

For a hydrodynamic bearing to function properly, it was necessary to use a lubricating fluid feed system if the circuit was of the open type, or a recirculation system when the circuit was a closed type. 


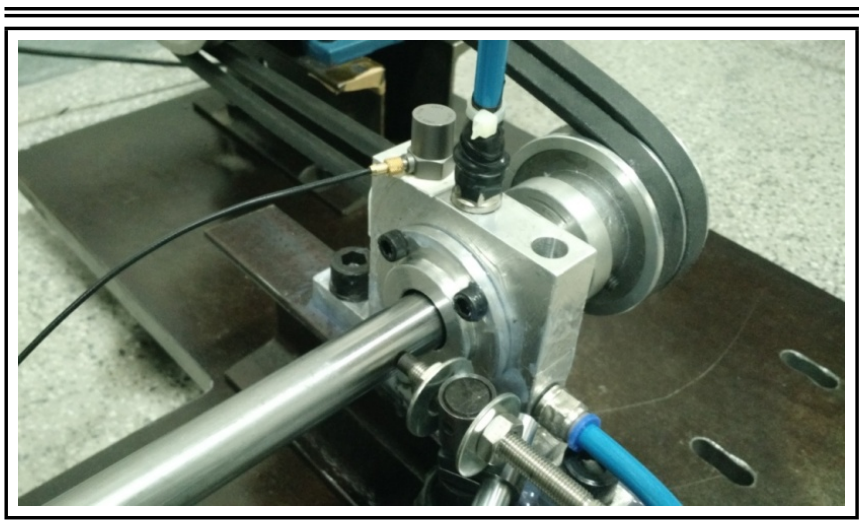

Figure 2. Developed bearing.

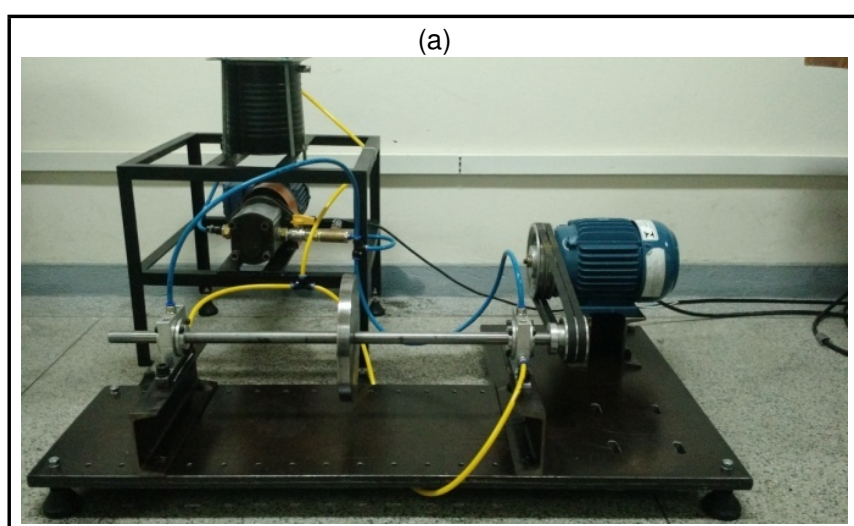

(b)

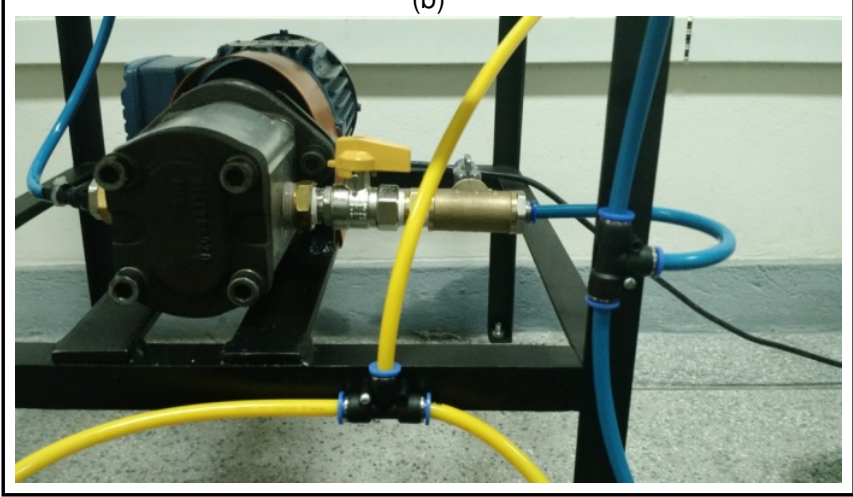

Figure 3. Test rig with fluid feed system: (a) general view and (b) distribution detail.

In this work, a closed loop system was developed for oil recirculation. The oil was stored in a reservoir, then through PU-8 hoses that can withstand pressures of up to $1.3 \mathrm{MPa}$, and finally dispensed using an onestage gear type pump for the two bearings (Fig. 3a). The return of the oil was also done with the hoses towards the reservoir. For the system to not be overpressured when the machine was switched off, a direct line with the reservoir was made after the pump output. The oil flow control for the bearings was made through a sphere valve and the control for opening and closing the drain path was also made with a sphere valve (Fig. 3b).

The outlet pressure of the pump was $50 \mathrm{kPa}$ and, after considering the effects of the pressure drop, the pressure at the work points was $49.984 \mathrm{kPa}$. It may be noted that the system had not suffered a significant loss of load therefore for the operation of the hydrodynamic bearing the pressure exerted by the hydraulic unit was sufficient for feeding the lubricating fluid.

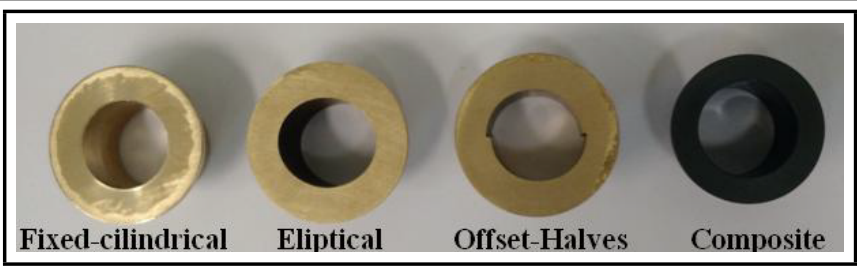

Figure 4. Different kind of bushings used for the tests.

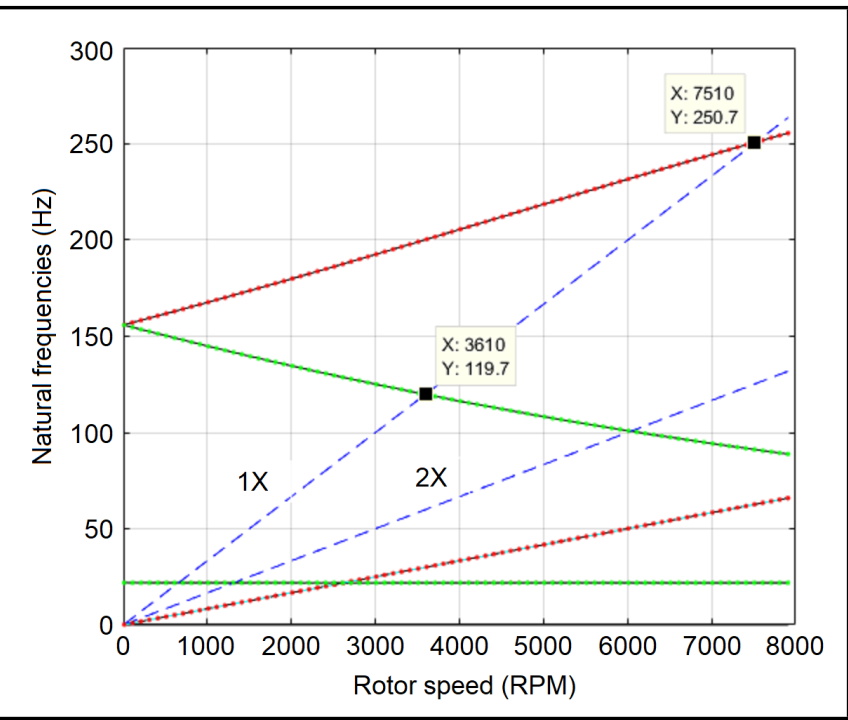

Figure 5. Campbell diagram.

\subsection{Numerical Simulation}

The rotor was simulated using MATLAB program with the same hydrodynamic bearing parameters and rotor dimensions. The program used was based on finite element modelling of the rotor, dividing the model in 12 Euler-Bernoulli beam elements. $^{25}$ The program generated plots including: Campbell diagram, unbalance disk response excitation, mode shapes, orbits, and bearing-shaft eccentricity.

\subsection{Bush Geometries}

The variation of geometries of the bushing is illustrated on Fig. 4. The fixed-cylindrical bush was described above, the elliptical had an eccentricity degree of 0.42 and the offset-halves had an asymmetry estimated by $1 \mathrm{~mm}$ in radial direction. The composite bushing had the same geometry characteristics of the first one, the material had a self-lubrication property. Besides of this material, the composite bushing was lubricated with grease (Molybdenum disulphide main chemical component).

\section{RESULTS AND DISCUSSION}

\subsection{Simulation Results}

Figure 5 presents the Campbell diagram of the rotor with a couple of hydrodynamic bearing with fixed cylindrical bushes. The diagram shows the evolution of natural frequencies while the rotor speed changes. The two points highlighted (3610 and 7510 RPM, i.e, 60.17 and $125.17 \mathrm{~Hz}$ ) are the critical speeds that are related to the third and fourth modes (presented in Fig. 6). These modes have conical shapes, where the gyroscopic effect can change the natural frequency. 


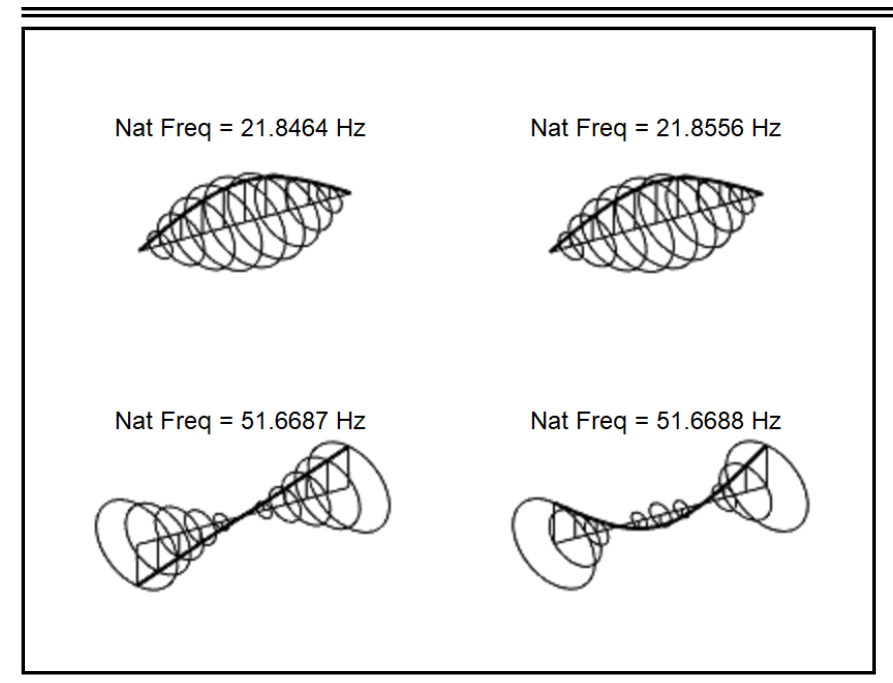

Figure 6. Mode shapes.

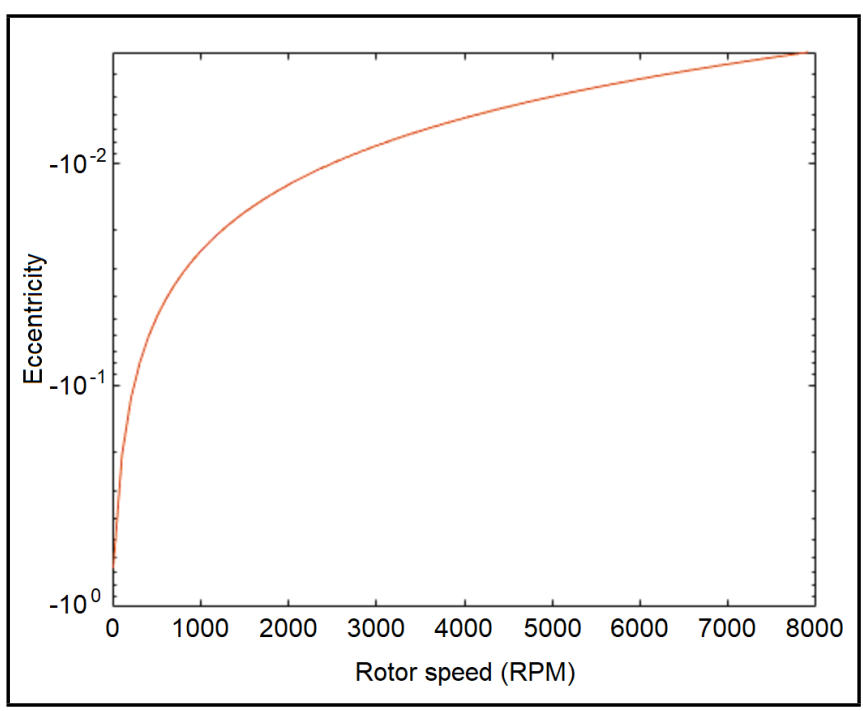

Figure 7. Eccentricity variation.

Due to symmetrical configuration of the rotor, the orbit plots are all cylindrical and without differences between the rotation movement and center shaft movement. Figure 7 illustrates the evolution of hydrodynamic bearing eccentricity, for high speeds the eccentricity tends to be zero, which is expected for the rotor operation.

\subsection{Instability Evaluation}

From the matrix motion equation, Eq. (1), the state space solution is made and then the Jacobian matrix operation of the function. Applying the Routh-Hurwitz stability criterion to the characteristic equation with the Jacobian matrix, the limits of instability are found.

For the calculation to be simpler, there are two cases for the bearings: 1st Case as a short bearing approximation; 2nd Case as an approximation as a long bearing. ${ }^{13}$ Reddy and Srinivas make an analysis through the use of finite elements of a bisupported rotor, experiencing excitation at its base, considering its support element as a short type bearing. ${ }^{26}$ In this work, the designed bearing has an $L / D$ ratio of $<1$, that is, it can also be considered as a short type bearing. ${ }^{13}$ For the short bearing condition, the parameters of stiffness and damping are presented
Table 2. Dynamic parameters of developed bearing.

\begin{tabular}{|c|c|c|}
\hline Direction & Siffness [MN/m] & Damping [kN s/m] \\
\hline XX & 1.27493 & 100.097 \\
XY & -49.9414 & 2.54592 \\
YX & 50.0662 & 2.54592 \\
YY & 0.60029 & 99.9579 \\
\hline
\end{tabular}

Table 3. Stability analysis for the developed bearing.

\begin{tabular}{|c|c|c|c|}
\hline$\lambda_{n}$ & $1^{\circ}$ column & $2^{\circ}$ column & $3^{\circ}$ column \\
\hline$\lambda_{4}$ & 37.3 & $9.7 \cdot 10^{9}$ & $2.5 \cdot 10^{15}$ \\
$\lambda_{3}$ & $1.2 \cdot 10^{6}$ & $5.14 \cdot 10^{12}$ & 0 \\
$\lambda_{2}$ & $9.7 \cdot 10^{9}$ & $2.5 \cdot 10^{15}$ & 0 \\
$\lambda_{1}$ & $4.8 \cdot 10^{12}$ & 0 & 0 \\
$\lambda_{0}$ & $2.5 \cdot 10^{15}$ & 0 & 0 \\
\hline
\end{tabular}

by Huang et al., following the system of equations: ${ }^{13}$

$$
\begin{aligned}
k_{x x}= & \frac{4\left[2 \pi^{2}+\left(16-\pi^{2}\right) \varepsilon^{2}\right]}{\left[\pi^{2}+\left(16-\pi^{2}\right) \varepsilon^{2}\right]^{3 / 2}} ; \\
k_{x y}= & \frac{\pi\left[-\pi^{2}+2 \pi^{2} \varepsilon^{2}+\left(16-\pi^{2}\right) \varepsilon^{4}\right]}{\varepsilon\left(1-\varepsilon^{2}\right)^{1 / 2}\left[\pi^{2}+\left(16-\pi^{2}\right) \varepsilon^{2}\right]^{3 / 2}} \\
k_{y x}= & \frac{\pi\left[\pi^{2}+\left(32+\pi^{2}\right) \varepsilon^{2}+2\left(16-\pi^{2}\right) \varepsilon^{4}\right]}{\varepsilon\left(1-\varepsilon^{2}\right)^{1 / 2}\left[\pi^{2}+\left(16-\pi^{2}\right) \varepsilon^{2}\right]^{3 / 2}} \\
k_{y y}= & \frac{4\left[\pi^{2}+\left(32+\pi^{2}\right) \varepsilon^{2}+2\left(16-\pi^{2}\right) \varepsilon^{4}\right]}{\left(1-\varepsilon^{2}\right)^{1 / 2}\left[\pi^{2}+\left(16-\pi^{2}\right) \varepsilon^{2}\right]^{3 / 2}} \\
c_{x x}= & \frac{2 \pi\left(1-\varepsilon^{2}\right)^{1 / 2}\left[\pi^{2}+2\left(\pi^{2}-8\right) \varepsilon^{2}\right]}{\varepsilon\left[\pi^{2}+\left(16-\pi^{2}\right) \varepsilon^{2}\right]^{3 / 2}} \\
c_{x y}= & c_{y x}=\frac{8\left[\pi^{2}+2\left(\pi^{2}-8\right) \varepsilon^{2}\right]}{\left[\pi^{2}+\left(16-\pi^{2}\right) \varepsilon^{2}\right]^{3 / 2}} \\
c_{y y}= & \frac{2 \pi\left[\pi^{2}+2\left(24-\pi^{2}\right) \varepsilon^{2}+\pi^{2} \varepsilon^{4}\right]}{\varepsilon\left(1-\varepsilon^{2}\right)^{1 / 2}\left[\pi^{2}+\left(16-\pi^{2}\right) \varepsilon^{2}\right]^{3 / 2}}
\end{aligned}
$$

Applying the eccentricity value as being equal to 0.02 in the equations of the rigidity and damping parameters for short type bearings of the work of Huang et al., ${ }^{13}$ the dynamic parameters are shown in Table 2.

With these values, after applied in matrix Eq. (1) the characteristic equation is obtained:

$$
\begin{gathered}
37.3 \lambda^{4}+1.2 \cdot 10^{6} \lambda^{3}+9.7 \cdot 10^{9} \lambda^{2}+5.14 \cdot 10^{12} \lambda+ \\
2.5 \cdot 10^{15}=0
\end{gathered}
$$

where $\lambda$ represents the complex roots of the equation of motion that indicate that the transient motion of the axis will take a harmonic waveform with a decay of amplitude when the system is stable, that is, when the real parts from $\lambda$ are all negative. The complex parts from represent the frequency of the resulting vibrations.

There is interest to predict if the system is stable or not. To analyse this, the Routh-Hurwitz stability criterion is applied in Eq. (3). This criterion is based on the verification of the variation of the signal of the real part of $\lambda$. Therefore, for a system to be stable there must be no changes in the first column of the result table obtained (Table 3).

When analysing the first column of Table 3 , the coefficients obtained do not change signal, so the developed system of the hydrodynamic bearing is stable even though the asymmetry in the values of rigidity and the presence of the eccentricity in its assembly. Another point to be highlighted is the difference of the rigidity values in the horizontal and vertical direction (Table 2), which although small, is of the order of two times in 


\begin{tabular}{|c|c|c|c|}
\hline $\begin{array}{l}\text { Operation condition } \\
\quad \text { (direction) }\end{array}$ & $\begin{array}{l}\text { Bearing on } \\
\text { DE }[\mathrm{Hz}]\end{array}$ & $\begin{array}{l}\text { Bearing on } \\
\mathrm{NDE}[\mathrm{Hz}]\end{array}$ & $\begin{array}{c}\text { Bearing on } \\
\text { DE and NDE } \\
\text { (results: } \\
\text { DE / NDE) }[\mathrm{Hz}]\end{array}$ \\
\hline Run-up (horizontal) & 120.09 & 120.28 & $119.79 / 119.89$ \\
\hline Run-up (vertical) & 51.34 & 80.59 & $51.28 / 51.66$ \\
\hline Coast-down (horizontal) & 119.33 & 99.89 & $119.99 / 124.62$ \\
\hline Coast-down (vertical) & 51.42 & 81.47 & $51.83 / 52.22$ \\
\hline
\end{tabular}

Table 5. Critical speeds with offset-halves bushing.

\begin{tabular}{|c|c|c|}
\hline $\begin{array}{c}\text { Operation condition } \\
\text { (direction) }\end{array}$ & $\begin{array}{c}\text { Bearing on } \\
\text { DE [Hz] }\end{array}$ & $\begin{array}{c}\text { Bearing on } \\
\text { NDE [Hz] }\end{array}$ \\
\hline Run-up (horizontal) & 50.34 & 51.26 \\
Run-up (vertical) & 50.89 & 51.35 \\
Coast-down (horizontal) & 51.41 & 50.50 \\
Coast-down (vertical) & 51.90 & 50.65 \\
\hline
\end{tabular}

relation to another. Showing that the bearing is more flexible in the vertical direction (due to the support of the oil film) than in the horizontal direction. There was no intention to obtain the eigenvalues from Eq. (3).

\subsection{Experimental Results}

The set of hydrodynamic bearings is mounted on the bench using the same bearing points from which the bearing was attached. This fixation is provided by bolts with a U-beam base that is mounted on the base of inertia. To prevent any effects of misalignment in the test rig, the rotor was aligned using dial indicators with a tolerance of maximum of $0.002 \mathrm{~mm}$ between the two bearings to guarantee the film oil formation inside the bearing. For the experimental measurements, 3 bearing conditions were analysed: rolling bearing in the driven end (DE) position and hydrodynamic bearing on non-driven end (NDE) position; hydrodynamic on DE and ball bearing on NDE; and hydrodynamic on DE and NDE sides. These variations on positions are needed to verify the torque influences by the drive system. There is no necessity for applying ball bearings in both positions because the same experiment had already been carried out. $^{24}$

Table 4 presents the values of the dominant frequencies for the transient working condition of the Jeffcott rotor. From the obtained values, it is possible to confirm the anisotropic characteristic of the hydrodynamic bearing, which is independent of the region where it is mounted, by showing that the bearing has less rigidity in the vertical direction and lower values of natural frequencies than in the horizontal direction.

In addition to this finding, it is also possible to realize that, when different kinds of bearings are mounted, the global support behaviour for the rotor follows the support element used on the region of application of the torque (DE). Thus, demonstrating an important relationship between torque and its influence on the dynamic behaviour of hydrodynamic bearings.

The analysis for the two positions (DE and NDE) shows there is no significant torque influences caused by the drive system using pulleys and belts transmission, the natural frequencies obtained are very similar. The DE and NDE condition also show a clear anisotropic effect caused by hydrodynamic bearing, which is expected in accord to other authors and confirm the correct design, assembly and operation condition for hydrodynamic bearings.

The next tests are based of varying the bush geometry. Tables 5-7 show the results for offset-halves, elliptical and com-
Table 6. Critical speeds with elliptical bushing.

\begin{tabular}{|c|c|c|}
\hline $\begin{array}{c}\text { Operation condition } \\
\text { (direction) }\end{array}$ & $\begin{array}{c}\text { Bearing on } \\
\mathrm{DE}[\mathrm{Hz}]\end{array}$ & $\begin{array}{c}\text { Bearing on } \\
\text { NDE [Hz] }\end{array}$ \\
\hline Run-up (horizontal) & 44.63 & 47.12 \\
Run-up (vertical) & 50.20 & 50.35 \\
Coast-down (horizontal) & 44.42 & 45.67 \\
Coast-down (vertical) & 51.94 & 49.80 \\
\hline
\end{tabular}

Table 7. Critical speeds with composite material bushing and solid lubrification.

\begin{tabular}{|c|c|c|}
\hline $\begin{array}{c}\text { Operation condition } \\
\text { (direction) }\end{array}$ & $\begin{array}{c}\text { Bearing on } \\
\text { DE [Hz] }\end{array}$ & $\begin{array}{c}\text { Bearing on } \\
\text { NDE [Hz] }\end{array}$ \\
\hline Run-up (horizontal) & 45.49 & 46.78 \\
Run-up (vertical) & 44.79 & 43.66 \\
Coast-down (horizontal) & 43.87 & 44.44 \\
Coast-down (vertical) & 42.08 & 45.61 \\
\hline
\end{tabular}

posite material bushing respectively. The critical speeds detected are much closer than in cylindrical bushes, showing an optimization for isotropic dynamic behaviour.

\section{CONCLUSIONS}

From the work developed the main conclusions obtained were:

- A short procedure applied to develop a set of hydrodynamic bearings applied to a Jeffcott test rig, considering all the dynamic influences that this bench can promote. The bearing has a stable dynamic behaviour based on analytic analysis. The effect of anisotropy was well detected when a fixed-cylindrical bushing was used (Table 4) To decrease this effect, different designs of bushings were applied: offset-halves (Table 5), elliptical bore (Table 6) and a composite material bushing and solid lubrication (Table 7).

- The results comparison between numerical simulation (Fig. 5) and experimental results (Table 4) showed a difference up to $10 \%$ between results obtained by Campbell diagram and the experimental results measured in vertical direction. This difference drops to $4.5 \%$ when the horizontal direction is analysed. This comparison among the experimental results and numerical simulation (including orbit analysis, mode shapes and Campbell diagram) is important to predict critical speeds for rotors with hydrodynamic bearings.

\section{REFERENCES}

1 ISO 1925, Balancing Vocabulary, International Organization for Standardization, (2001).

2 Allmaier, H., Sander, D. E., and Reich, F. M. Simulating friction power losses in automotive journal bearings, Procedia Engineering, 68, 49-55, (2013). https://dx.doi.org/10.1016/j.proeng.2013.12.146

3 Petersen, D., Howard, C., Sawalhi, N., and Moazen, A. Analysis of bearing stiffness variations, contact forces and vibrations in radially loaded double row rolling element bearings with raceway defects, Mechanical Systems and Signal Processing, 51, 139-160, (2015). https://dx.doi.org/10.1016/j.ymssp.2014.04.014 
4 Taplak, H., Erkaya, S., and Uzmay, I. Experimental analysis on fault detection for a direct coupled rotorbearing system, Measurement: Journal of the International Measurement Confederation, 46 (1), 336-344, (2013). https://dx.doi.org/10.1016/j.measurement.2012.07.005

5 Loeffler, C. F., Chacaltana, J. T. A., Frasson, A. M. F., and Mansur, W. J. Simulation of the journal bearing hydrodynamic using two boundary element radial basis interpolation models, Engineering Analysis with Boundary Elements, 105, 188-193, (2019). https://dx.doi.org/10.1016/j.enganabound.2019.04.021

6 Garoli, G. Y. and de Castro, H. F. Analysis of a rotor-bearing nonlinear system model considering fluidinduced instability and uncertainties in bearings, Journal of Sound and Vibration, 448, 108-129, (2019). https://dx.doi.org/10.1016/j.jsv.2019.02.021

7 Ramos, D. J. and Daniel, G. B. A new concept of active hydrodynamic bearing for application in rotating systems, Tribology International, 153, 106592, (2021). https://dx.doi.org/10.1016/j.triboint.2020.106592

8 Taşgin, Y. and Kahraman, G. Crack failure in hydrodynamically lubricated bearings: A case study hydraulic turbine, Engineering Failure Analysis, 105123, (2020). https://dx.doi.org/10.1016/j.engfailanal.2020.105123

9 Li, K., Liu, J., Han, X., Jiang, C., and Qin, H. Identification of oil-film coefficients for a rotor-journal bearing system based on equivalent load reconstruction, Tribology International, 104, 285-293, (2016). https://dx.doi.org/10.1016/j.triboint.2016.09.012

10 Synnegård, E., Gustavsson, R., and Aidanpää, J. Influence of cross-coupling stiffness in tilting pad journal bearings for vertical machines, International Journal of Mechanical Sciences, 111-112, 43-54, (2016). https://dx.doi.org/10.1016/j.ijmecsci.2016.03.017

11 Mazer, T. T. Cálculo em elementos finitos das frequências naturais dos modos de flexão de uma linha de eixo de unidade geradora hidráulica em escala, Master thesis, UNESP, Guaratinguetá, (2016).

12 Wang, S., Bi, C., Li, J., and Zheng, C. Parametric instability of anisotropic rotor-bearing systems with a transverse crack, Journal of Sound and Vibration, 443, 253-269, (2019). https://dx.doi.org/10.1016/j.jsv.2018.11.052

13 Huang, Y., Tian, Z., Chen, R., and Cao, H. A simpler method to calculate instability threshold speed of hydrodynamic journal bearings, Mechanism and Machine Theory, 108, 209-216, (2017). https://dx.doi.org/10.1016/j.mechmachtheory.2016.11.009

14 Ganguly, S., Neogy, S., and Nandi, A. On lumping of gyroscopic matrix in finite element analysis of rotors, Procedia Engineering: 12th International Conference on Vibration Problems, 144, 398-405, (2016). https://dx.doi.org/10.1016/j.proeng.2016.05.149
15 Sorge, F. Preventing the oil film instability in rotordynamics, Journal of Physics: Conference Series, 744, 1-14, (2016). https://dx.doi.org/10.1088/1742$6596 / 744 / 1 / 012153$

16 Bhasker, B., Seetharamaiah, N., and Babu, P. R. Experimental investigation of hydrodynamic pressure and oil film temperature of surface textured offset halves journal bearing, Materials Today: Proceedings, (2021). https://dx.doi.org/10.1016/j.matpr.2020.10.558

17 Rahmani, F., Pandey, R. K., and Dutt, J. K. Influence of elliptic bore and non-newtonian rheology of lubricant on the performance and stability of journal bearing, Procedia Technology, 23, 28-35, (2016). https://dx.doi.org/10.1016/j.protcy.2016.03.069

18 Van Ostayen, R. A. J. and van Beek, A. Thermal modelling of the lemon-bore hydrodynamic bearing, Tribology International, 42, 23-32, (2009). https://dx.doi.org/10.1016/j.triboint.2008.05.013

19 Urbiola-Soto, L., Ram, A. C., and Ya, R. Rotordynamic optimization of fixed pad journal bearings using response surface design of experiments, Journal of Engineering for Gas Turbines and Power, 138, 1-10, (2017). https://dx.doi.org/10.1115/1.4034066

20 Ding, L., Zhu, H., and Wu, L. Analysis of mechanical properties of laminated rubber bearings based on transfer matrix method, Composite Structures, 159, 390-396, (2017). https://dx.doi.org/10.1016/j.compstruct.2016.09.074

21 Litwin, W. Properties comparison of rubber and three layer PTFE-NBR-bronze water lubricated bearings with lubricating grooves along entire bush circumference based on experimental tests, Tribology International, 90, 404-411, (2015). https://dx.doi.org/10.1016/j.triboint.2015.03.039

22 Choe, K. Y., On, S. Y., Song, S. A., Lim, J. W., You, J. I., and Kim, S. S. Study of the endurance performance of composite journal bearings under the oil cut situation, Composite Structures, 134, 772-781, (2015). https://dx.doi.org/10.1016/j.compstruct.2015.08.122

23 Simmons, G. F., Cerda, A., Ferreira, I., and Glavatskih, S. Dynamic characteristics of polymer faced tilting pad journal bearings, Tribology International, 74, 20-27, (2014). https://dx.doi.org/10.1016/j.triboint.2014.02.001

24 Medeiros, E. C., Mendonça, W. R. P., Barros, E., and Mathias, M. H. Design and evaluation of a researcheducational test bench applied to rotor dynamics studies, IEEE Latin America Transactions, 16 (8), 2161-2167, (2018). https://dx.doi.org/10.1109/tla.2018.8528230

25 Friswell, M., Penny, J., Garvey, S., and Lees, A. Dynamics of Rotating Machines, 1st ed., Cambridge University Press, New York, (2010). https://dx.doi.org/10.1017/cbo9780511780509

26 Reddy, M. R. and Srinivas, J. Vibration analysis of a support excited rotor system with hydrodynamic journal bearings, Procedia Engineering, 144, 825-832, (2016). https://dx.doi.org/10.1016/j.proeng.2016.05.093 